Available Online at https://akper-sandikarsa.e-journal.id

\author{
Jurnal Ilmiah Kesehatan \\ Sandi Husada
}

ISSN 2654-4563

\author{
Jurnal Ilmiah Kesehatan Sandi Husada \\ Vol.7,Issue, 1, pp. 1403-1407, Juni 2019
}

\title{
Research Article \\ GAMBARAN TINGKAT PENGETAHUAN LANSIA TERHADAP HIPERTENSI DI PUSKESMAS KAMPALA SINJAI
}

\author{
${ }^{1}$ Nur Syamsi N.L, ${ }^{2}$ A. Syamsinar Asmi \\ 12 Prodi DIII Keperawatan Sandi Karsa
}

ARTICLE INFO
Article History:
Received April 2019
Juni, 2019 Published online

Key Words:

Pengetahuan,

Sikap,hipertensi,Lansia

\section{ABSTRAK}

Pendahuluan,Indonesia merupakan negara yang memiliki wilayah yang luas dengan jumlah penduduk yang sangat besar. Hal ini menjadi tantangan tersendiri bagi tercapainya tujuan pembangunan kesejahteraan melalui Indonesia sehat 2013, yaitu untuk meningkatkan kesadaran, kemauan dan kemampuan hidup sehat bagi setiap orang agar terwujud derajat kesehatan masyarakat yang optimal melalui terciptanya masyarakat, bangsa dan negara Indonesia yang ditandai oleh penduduknya hidup dalam lingkungan dan dengan perilaku kesehatan yang optimal.

Tujuan penelitian, memperoleh gambaran secara umum tentang tingkat pengetahuan lansia terhadap hipertensi di Puskesmas kampala sinjai.

Metode penelitian, Desain penelitian yang digunakan adalah metode deskriptif karena berujuan untuk menggambarkan keadaan atau status fenomena. Dalam hal ini peneliti hanya ingin mengetahui hal-hal yang berhubungan dengan keadaan sesuatu. Penelitian ini menggunakan desain penelitian deskriptif yang akan mengukur/menilai pengetahuan dan sikap lansia terhadap hipertensi di puskesmas kampala sinjai.

Hasil, Diperolehnya gambaran tentang pengetahuan lanjut usia terhadap hipertensi di wilayah kerja puskesmas kampala sebanyak 25 responden didapatkan pengetahuan baik sebanyak 2 orang $(8 \%)$, pengetahuan cukup 21 orang (84\%), pengetahuan kurang 2 orang (8\%).Diperolehnya gambaran sikap lanjut usia diwilayah kerja puskesmas kampala sebanyak 25 reponden didapatkan tingkat bersikap baik sebanyak 11 orang ( $44 \%$ ), bersikap buruk sebanyak 13 orang ( $52 \%$ ).

Kesimpulan, meningkatkan keilmuan dan mutu asuhan keperawatan yang di berikan,di harapkan di perhatikan pengembangan informasi khususnya tentang pengetahuan dan sikap yang erat hubungannya terhadap hipertensi.Sehingga baik masyarakat khususnya lansia dan perawat atau pekerja sosial sebagai pemberi pelayanan mendapat kepuasan masing-masing. Pihak Puskesmas agar meningkatkan kemampuan petugas kesehatan, baik itu dokter maupun perawat serta perawat-perawat desa agar kiranya memberikan penyuluhan atau health education tentang pengetahuan dan sikap lansia terhadap hipertensi. 


\section{Pendahuluan}

Indonesia merupakan negara yang memiliki wilayah yang luas dengan jumlah penduduk yang sangat besar. Hal ini menjadi tantangan tersendiri bagi tercapainya tujuan pembangunan kesejahteraan melalui Indonesia sehat 2013, yaitu untuk meningkatkan kesadaran, kemauan dan kemampuan hidup sehat bagi setiap orang agar terwujud derajat kesehatan masyarakat yang optimal melalui terciptanya masyarakat, bangsa dan negara Indonesia yang ditandai oleh penduduknya hidup dalam lingkungan dan dengan perilaku kesehatan yang optimal di seluruh wilayah Republik Indonesia

Untuk mendukung terciptanya hal tersebut, harus di dahului dengan peningkatan derajat kesehatan di tingkat individu, keluarga, kelompok baik di kota maupun di desa. Kelompok masyarakat kota maupun masyarakat desa masing-masing memiliki masalah kesehatan yang kompleks dan menumbuhkan perhatian khusus untuk pemecahan kondisi masyarakat perkotaan yang padat, kesibukan yang banyak dan sebagian berada pada pemukiman kumuh menjadi masalah semakin sulit ditangani. Kondisi kesehatan masyarakat suatu bangsa merupakan salah satu indicator keberhasilan dan kesejahteraan masyarakat sehingga dalam pembangunan kesehatan, partisipasi masyarakat menempati posisi yang lebih penting karena tanpa kesadaran individu dan masyarakat itu sendiri maka kebijakan apapun yang diterapkan oleh pemerintah dalam menjaga kesehatan masyarakat hanya sebagian kecil yang tercapai.

Di Indonesia merupakan masyarakat yang terdiri dari bermacam-macam suku dengan pola kebiasaan yang berbeda-beda pula. Salah satu contoh kebiasaan masyarakat yaitu dari segi pola hidup misalnya makanan yang dikonsumsi dan kurang aktifitas serta stress yang berlebihan.

Berdasarkan kebiasaan-kebiasan diatas dapat menimbulkan berbagai macam penyakit. Salah satunya adalah penyakit hipertensi. Hipertensi adalah peningkatan tekanan darah sistolik $\geq 140 \mathrm{mmHg}$ dan tekanan darah diastolic $\geq 90 \mathrm{mmHg}$ (Sarwono, $W$, 2010)

Untuk mencegah terjadinya komplikasi seperti stroke, gagal ginjal, kerusakan penglihatan, dan gagal jantung maka sangat diperlukan tenaga keperawatan yang mempunyai pengetahuan dan keterampilan yang memadai.

Menurut Health Survey for England 2002 yang dilakukan Departemen Kesehatan Inggris, Persentase penderita Hipertensi pada sejak usia 16 - 24 tahun memang masih kecil. Persentase Hipertensi pada usia diatas 60 tahun yaitu antara $70-80 \%$.

\section{Kajian Literatur \\ Pengertian Lansia}

Menua (menjadi tua) adalah suatu proses menghilangnya secara perlahan-lahan kemampuan jaringan untuk memperbaiki diri/mengganti dan mempertahankan fungsi normalnya sehingga tidak dapat bertahan terhadap infeksi dan memperbaiki kerusakan yang diderita (Constantinides, 1994).

Proses menua merupakan suatu proses yang terus menerus (berlanjut) secara alamiah. Dimulai sejak lahir dan umumnya dialami pada semua makhluk hidup.Proses menua setiap individu pada organ tubuh juga tidak sama cepatnya. Adakalanya orang belum tergolong lanjut usia (masih muda) akan tetapi kekurangan-kekurangan yang menyokok (Deskripansi) (Constantinides,1994)

Menurut Undang-undang no.9 tahun 1960 tentang Pokok-pokok Kesehatan pasal 8 ayat 2, berbunyi: dalam istilah sakit termasuk cacat, kelemahan, dan lanjut usia.

Berdasarkan pernyataan tersebut, maka lanjut usia dianggap sebagai semacam penyakit. Hal ini tidak benar. Gerontologi berpendapat lain, sebab lanjut usia bukan suatu penyakit, melainkan suatu masa atau tahap hidup manusia, yaitu Bayi, kanak-kanak, dewasa, tua, dan lanjut usia. Orang mati tidak karena lanjut usia tetapi karena sesuatu penyakit, atau juga suatu kecelakaan, atau menurut orang beragama, sebagai contoh dikatakan, dicabut nyawa seseorang oleh Malaikat Izrail atas kehendak Allah (Pudjiastuti,2010).

Menua bukanlah suatu penyakit akan tetapi merupakan proses berkurangnya daya tahan tubuh dalam menghadapi rangsangan dari dalam maupun dari luar. Walaupun demikian memang harus diakui bahwa ada berbagai penyakit yang sering menghinggapi kaum lanjut usia. Proses menua sudah mulai berlangsung sejak seseorang mencapai usia dewasa, misalnya dengan terjadinya kehilangan jaringan pada otot, susunan syaraf, dan jaringan lain sehingga tubuh "mati" sedikit demi sedikit (Pudjiastuti,2010).

Sebenarnya tidak ada batas yang tegas, pada usia berapa penampilan seseorang mulai menurun. Pada setiap orang, fungsi fisiologis alat tubuhnya sangat berbeda, baik dalam hal pencapaian puncak maupun scat menurunnya. Hal ini juga sangat individual. Namun demikian umumnya, fungsi fisiologis tubuh mencapai puncaknya pada umur antara 20 dan 30 tahun. Setelah mencapai puncak, fungsi alat tubuh akan berada dalam kondisi tetap utuh beberapa saat, kemudian menurun sedikit demi sedikit sesuai dengan bertambahnya umur.

Sampai saat ini banyak sekali teori yang menerangkan "proses menua" mulai dari teori degeneratif yang didasari oleh habisnya daya 
cadangan vital, teori terjadinya atrofi, yaitu teori yang mengatakan bahwa proses menua adalah proses evolusi, dan teori imunologik, yaitu teori adanya produk sampah / waste products dari tubuh sendiri yang makin bertumpuk.Tetapi seperti diketahui bahwa lanjut usia akan selalu bergandengan dengan perubahan fisiologik maupun psikologik. Yang penting untuk diketahui bahwa aktivitas fisik dapat menghambat atau memperlambat kemunduran fungsi tubuh yang disebabkan oleh bertambahnya umur (Pudjiastuti, 2010).

\section{Pengetahuan}

Pengetahuan adalah hasil dari tahu, dan ini terjadi setelah orang melakukan pengindraan terhadap suatu objek tertentu, yang dimaksud objek dalam pengetahuan adalah benda atau hal yang diselidiki oleh pengetahuan sehingga tidak menimbulkan kecemasan pada individu itu sendiri (Notoatmojo 2010).

Pada hakikatnya merupakan segenap apa yang kita ketahui tentang suatu objek dan setiap jenis pengetahuan mempunyai ciri-ciri spesifik mengenai ap (ontology), bagaimana (epitemologi) dan untuk apa (aksiologi) sehingga tidak ada timbul kecemasan pada setiap individu

Tingkat pengetahuan

Pengetahuan adalah hasil dari tahu dan ini terjadi setelah seseorang melakukan peginderaan terhadap suatu objek tertentu. Menurut (Natoatmodjo, 2010) ada 6 tingkatan pengetahuan yaitu :

a. Tahu (Know), Tahu adalah mengingat suatu materi yang telah dipelajari sebelumnya, termasuk dalam tingkat pengetahuan ini adalah mengingat kembali (Recall) terhadap suatu yang spesifik dari seluruh bahan yang dipelajari merupakan tingkat pengetahuan yang paling rendah. Kata kerja untuk mengukur bahwa orang tahu tentang apa yang dipelajari antara lain menyebutkan, menguraikan dan sebagainya.

b. Memahami(Comprehension),Dalam memahami tersebut adalah suatu kemampuan untuk menjelaskan secara benar tentang objek diketahui dan dapat menginterprestasikan materi secara benar. Orang yang telah pahamterhadap objek atau materi harus dapat menjelaskan, menyebutkan contoh terhadap objek yang dipahami.

c. Aplikasi (Application), Diartikan sebagai suatu kemampuan untuk menggunakan materi yang telah dipelajari pada situasi dan kondisi real. Aplikasi ini dapat diartikan sebagai penggunaan hukum-hukum, rumus dan prinsip.

d. Analisis (Analysis) ,merupakan kemampuan untuk menjabarkan materi sesuatu objek kedalam komponen-komponen tapi masih dalam struktur organisasi tersebut dan ada kaitanya antara satu sama lain. Kemampuan analisis ini dapat dilihat dari pengguanaan kata-kata kerja dengan menggambarkan, membedakan dan memisahkan.

e. Sintesis (Synthesis),Kemampuan untuk meletakkan atau menghubungkan bagian-bagian didalam suatu bentuk keseluruhan baru. Dengan kata lain sintesis ini adalah suatu kemampuan untuk menyusun formulasi. Dari formulasi yang ada, misalnya dapat menyusun, merencanakan merangkumkan fan menyesuaikan terhadap teori atau rumusan yang telah ada.

f. Evaluasi (Evaluation), evaluasi berkaitan dengan kemampuan untuk melakukan justifikasi atau penilaian terhadap suatu materi atau objek. Penilaian in berdasarkan kriteria yang ditentukan sendiri atau menggunakan kriteria-kriteria yang telah ada. Pengetahuan seseorang terhadap suatu objek dapat berubah dan berkembang sesuai dengan kemampuan, kebutuhan, pengalaman dan tinggi rendahnya mobilitas, informasi tentang objek tersebut.

\section{Pengertian Sikap}

Sikap merupakan reaksi atau respons yang masih tertutup dari seseorang terhadap suatu stimulasi atau objek. Sikap secara nyata menunjukkan konotasi adanya kesesuaian reaksi terhadap stimulus tertentu yang dalam kehidupan sehari-hari merupakan suatu reaksi yang bersifat emosional terhadap stimulus sosial (Notoatmodjo, 2010).

Sikap merupakan kesiapan untuk bereaksi terhadap suatu objek dengan cara-cara tertentu. Kesiapan yang dimaksud disini adalah kecenderungan potensial untuk bereaksi dengan cara tertentu apabila individu dihadapkan pada stimulus yang menghendaki adanya respons (Azwar, 2010).

\section{Pengertian Hipertensi}

Hipertensi adalah tekanan darah istirahat diatas $140 \mathrm{mmHg}$ pada sistolik dan $90 \mathrm{mmHg}$ pada diastolik yang terjadi pada umur dibawah 50 tahun, sedangkan pada umur diatas 50 tahun dengan 160 mmHg pada sistolik dan $95 \mathrm{mmHg}$ pada diastolik, tetapi kriteria tersebut tidak mutlak pada setiap orang. (Toby Fagan, 2002)

Hipertensi adalah tekanan darah yang tinggi bersifat abnormal dan diukur paling tidak pada tiga kesempatan yang berbeda. Tekanan darah normal bervariasi sesuai usia, sehingga setiap diagnosa hipertensi harus bersifat spesifik-usia. Namun, secara umum seseorang dianggap mengalami hipertensi apabila tekanan darahnya lebih tinggi daripada 140 mmHg sistolik dan 90 mmHg diastolik (ditulis 140/90 mmHg). (Elizabeth J. Corwin, 2000).

Hipertensi adalah suatu peningkatan tekanan darah sistolik atau diastolik yang tidak normal. Batas sistolik 110 - $140 \mathrm{mmHg}$ dan diastolik antara 80 $95 \mathrm{mmHg}$. Nilai yang dapat diterima berbeda sesuai dengan usia dan jenis kelamin.

Hipertensi dapat didefinisikan sebagai tekanan darah persisten dimana tekanan sistoliknya diatas $140 \mathrm{mmHg}$ dan tekanan diastoliknya diatas 90 
mmHg. Pada populasi wanda, hipertensi merupakan penyebab utama gagal jantung, stroke, dan gagal ginjal. (Smeitzer, Zuzanne, 2001).

\section{Metode Penelitian}

Desain penelitian yang digunakan adalah metode deskriptif karena berujuan untuk menggambarkan keadaan atau status fenomena. Dalam hal ini peneliti hanya ingin mengetahui hal-hal yang berhubungan dengan keadaan sesuatu. Penelitian ini menggunakan desain penelitian deskriptif yang akan mengukur/menilai pengetahuan dan sikap lansia terhadap hipertensi di puskesmas kampala sinjai.

Populasi, adalah keseluruhan subjek yang diteliti (Arikunto, 2010). Populasi pada penelitian ini adalah semua lansia yang berada di wilayah kerja puskesmas kampala sinjai 50 orang. Sampel, adalah sebagian atau wakil populasi yang diteliti (Arikunto, 2010). cara pengambilan sampel dengan menggunakan purfosive sampling yaitu pengambilan data secara acak sesuai dengan kriteria ekslusi dan inklusi. Sampel pada penelitian ini adalah 25 responden yang berada di puskesmas kampala sinjai.

\section{Hasil}

Bahwa tingkat pengetahuan lanjut usia terhadap hipertensi di wilayah kerja puskesmas kamapala sinjai. memperlihatkan bahwa responden yang berpengetahuan baik berjumlah 2 responden (8\%),responden berpengetahuan cukup berjumlah 21responden (84\%)dan responden berpengetahuan kurang berjumlah 2 responden (8\%).

Menunjukkan bahwa secara umum tingkat pengetahuan lansia terhadap hipertensi di wilayah kerja puskesmas kampala sinjai sebagian besar menyatakan cukup (84\%), dan menyatakan baik (8\%). Sedangkan lainnya menyatakan kurang (8\%).Berdasarkan karakteristik responden dapat dijelaskan factor-faktor yang kemungkinan mempengaruhi tingkat pengetahuan lanjut usia terhadap hipertensi di wilayah kerja.

Pengetahuan dapat diperoleh melalui cara tradisional atau nonilmiah, cara kekerasan atau otoriter, berdasarkan pengalaman pribadi, melalui jalan pikiran sendiri arau cara modern. (Notoatmojo,2010).

Sikap merupakan reaksi atau respons yang masih tertutup dari seseorang terhadap suatu stimulasi atau objek.sikap secara nyata menunjukkan konotasi adanya kesesuaian reaksi terhadap stimulus tertentu yang dalam kehidupan sehari-hari merupakan suatu reaksi yang bersifat emosional terhadap stimulus social (Notoatmdojo,2010).

Hasil penelitian menunjukkan bahwa sikap lansia berdasarkan sikap yang di miliki,yaitu bersikap baik (44\%),sedangkan bersikap buruk (52).Data menunjukkan bahwa lebih banyak yang bersikap buruk daripada baik.

\section{Kesimpulan}

Dalam meningkatkan keilmuan dan mutu asuhan keperawatan yang di berikan,di harapkan di perhatikan pengembangan informasi khususnya tentang pengetahuan dan sikap yang erat hubungannya terhadap hipertensi.Sehingga baik masyarakat khususnya lansia dan perawat atau pekerja sosial sebagai pemberi pelayanan mendapat kepuasan masing-masing. Pihak Puskesmas agar meningkatkan kemampuan petugas kesehatan, baik itu dokter maupun perawat serta perawat-perawat desa agar kiranya memberikan penyuluhan atau health education tentang pengetahuan dan sikap lansia terhadap hipertensi.

\section{Kajian Literatur}

Adam, Syamsunir, Hygiene Perorangan, Bharata Niaga Media,Jakarta, 2009.

Anonoim, 2012, Inisiatif Kemitraan PemerintahSwasta Untuk Cuci Tangan Pakai Sabun; Available from : www.ampl.or.id), diakses 6 juli

, Jangan Anggap Remeh Diare Available from : www.medicastore.com, diakses 6 Juli

Azwar,Azrul,Pengantar IImu Kesehatan Lingkungan,Cetakan ke-8,Mutiara Sumber Widya, Jakarta, 2009.

Brunner \& Suddart. 202. Keperawatan Medikal Bedah., Jakarta : EGC

Chandra Budiman, 2010. PengantarKesehatanLingkungan. Jakarta: EGC

Depkes RI, 1995, Komunikasi Dengan Ibu Mengenai Pengobatan Diare di Rumah, Dirjen P2M \& PLP, Jakarta

Depkes RI 2010. Buku Pedoman Pelaksanaan Program P2 Diare di Puskesmas. Jakarta. Ditjen PPM PLP

Daud,Anwar,Dasar-Dasar Kesehatan Lingkungan, Fakultas KesehatanMasyarakat Universitas Hasanuddin, Makassar, 2010.

Fakultas Kesehatan Masyarakat, 2011, Penuntun Penyusunan Skripsi, FKM-UNPACTI, Makassar

Mulyono,2009. Hubungan Tingkat Pengetahuan Keluarga Tentang Diare dengan Sikap dan Perilaku Dalam Pencegahan Diare di Dusun Ngumpul, Jogoroto, Jombang.FKUI .Tidak di terbit

Ngastiyah. 2011. Perawatan Anak Sakit, Buku Kedokteran EGC

Noerasid H., Suraatmadja S. dan Asnil P.0., 2009, Gastro-enteritis (Diare) Akut, Diare Akut Klinik dan Laboratorik, PT Rineka Cipta, Jakarta.

Notoatmodjo, Soekodjo, 2010, IImu Kesehatan Masyarakat, Rineka Cipta,Cetakan.

Notoadmodjo, Soekidjo., 2009. Metode Penelitian Kesehatan. Jakarta 
Nur Syamsi N.L , et all, Gambaran Tingkat Pengetahuan Lansia Terhadap Hipertensi Di Puskesmas Kampala Sinjai 